\title{
How to mix per-flight and per-passenger based airport charges: The oligopoly case ${ }^{1}$
}

\author{
Achim I. Czerny², Simon Cowan ${ }^{3}$, and Anming Zhang ${ }^{4}$
}

February 10, 2017

\footnotetext{
${ }^{1}$ We thank Leo Basso, Markus Reisinger, Sun Yiqiao, the participants of the Economics Lunch seminar at the WHU - Otto Beisheim School of Management, the seminar participants at Hong Kong Polytechnic University, and especially the Associate Editor Robin Lindsey as well as two anonymous referees for their helpful comments and suggestions.

${ }^{2}$ Department of Logistics and Maritime Studies, Hong Kong Polytechnic University, achim.czerny@polyu.edu.hk.

${ }^{3}$ Department of Economics, University of Oxford, simon.cowan@economics.ox.ac.uk.

${ }^{4}$ Sauder School of Business, University of British Columbia, anming.zhang@sauder.ubc.ca.
} 


\begin{abstract}
While airport aeronautical charges are traditionally aircraft weight related, currently an increasing share of aeronautical airport revenues is derived from passenger related charges. This paper compares the optimal mix of per-passenger and per-flight based (cost recovering) airport charges from the carriers' and the social viewpoints when carrier markets are oligopolistic. We show that positive perpassenger charges might be able to support the implementation of monopoly fares at slot-constrained airports. They can also mitigate strategic frequency reductions at uncongested airports, leading to an increase in both carrier profit and welfare relative to a charging scheme that fully relies on per-flight charges.
\end{abstract}

Keywords: Airports; airlines; slots; schedule delays; congestion.

JEL: D40; H20; H40; L93; R48. 


\section{Introduction}

"Once an efficient level of costs has been duly justified through a meaningful consultation, the collection of these costs through passenger-based airport charges would provide increased transparency on what passengers pay for the use of airport facilities and services. They are the best charging method for sharing the risks and benefits of air traffic development between airport operators and airlines." (International Air Transport Association, IATA, 2016)

Joseph E. Stiglitz, who received the Nobel Memorial Prize in Economic Sciences in 2001 and was chief economist of the World Bank, pointed out that the supply of infrastructure at reasonable prices is crucial for the economic development of nations (Stiglitz, 1998). The present paper deals exactly with the question of what reasonable infrastructure prices really are. In the case of a simple infrastructure pricing scheme, the answer may be rather straightforward: Reduce infrastructure prices as long as they ensure sufficiently high revenues to cover infrastructure cost. Cost recovery is of policy importance because public funding is almost always limited and infrastructure supply is therefore conditional on cost recovery. However, infrastructure prices are typically not one-dimensional. Consider airports as an example (other examples would be sea ports or rail stations). Here infrastructure prices can roughly be divided into two groups. The first group contains infrastructure prices that are related to vehicle (i.e., aircraft) weight, while the second group contains infrastructure charges that are related to passengers. In fact, the International Civil Aviation Organisation (ICAO), a specialized agency of the United Nations that represents 191 member states, proposes that landing charges as well as parking and hangar charges should be based on aircraft-weight formulae (ICAO, 2012). On the other hand, airports worldwide derive today as much aeronautical revenues from per-passenger based charges as from aircraft related charges (ACI, 2008; ATRS, 2012). Airports often charge passengers for airport infrastructure development and/or debt repayment (Zhang, 2012). For instance, the construction cost for Hong Kong airport's third runway will be covered by an increase in the per-passenger based airport charges. Yet, IATA (International Air Transport Association), the trade association for the world's airlines, seems to propose to further move away from aircraft-weight related airport charges towards passenger based charges.

In a previous study, Czerny and Zhang (2015a) showed that the very fact that airlines express a preference for a zero aircraft-weight related charge can signal that the airport charges structure proposed by airlines is also optimal from the social viewpoint. The social viewpoint does capture airline profits but also the passengers' surplus derived from flying. This is a useful policy result, which they show to hold for both uncongested and congested airports, because it suggests that conflicts of interest between the airlines' and the social viewpoints can be easily detected by the airlines' statements on their preferred airport charges structure. ${ }^{1}$ Thus, there may be no need for policy makers to invest

\footnotetext{
${ }^{1}$ We consider an airport to be uncongested if its capacity is large enough to ensure that delays are zero for all relevant
} 
much effort to come up with their own judgement on airport charges structures as long as carriers have a preference for zero aircraft-weight related airport charges. However, Czerny and Zhang's results are based on a monopoly airline market. This view can be justified by the observation that many routes are indeed served by a single airline (e.g., Lazarev, 2013). Still, there is no doubt that many of the, perhaps, economically more important flight connections are offered by several airlines in parallel. This means that there is significant oligopolistic competition for passengers in the airline business.

That infrastructure charges can matter for competition between service providers that make use of the infrastructure has been found by Armstrong (1998) and Laffont et al. (1998a). They concentrated on fixed and customer related access charges for telecommunication networks and showed that telecommunication firms can approach the monopoly outcome by an increase in the customer related infrastructure charges. Thus, if policy makers would let telecommunications firms choose their infrastructure charges without restrictions, this could essentially eliminate the expected positive economic effects of competition between telecommunication firms. This raises the concern that a move from aircraft-weight related charges towards passenger based charges could be a concern for policy makers once airline competition is taken into account.

However, the results derived by Armstrong (1998) and Laffont et al. (1998a) are not directly applicable to air transport markets. Among the reasons are the following two, which will be addressed in the present paper. The first is related to the vertical structure of the air transport industry. While the mentioned analyses of telecommunication markets assumed that firms are vertically integrated in the sense that each company owns part of the overall telecommunication network, airline and airport markets are largely unintegrated (e.g., Basso and Zhang, 2007a and 2007b). This slightly complicates the analysis because airlines cannot directly choose airport charges but have to "convince" airports to implement their preferred airport charges structure. The second is related to service quality. In the case of airlines, flight charges can be considered as a fixed cost only if flight frequencies are fixed. Airline frequencies may indeed be fixed in the short run because airlines typically change their flight schedules every half year and because vehicle fleet expansions can take many years because of backlogs in the aircraft manufacturers' production plans. ${ }^{2}$ Fixed frequencies may also occur at slot-constrained airports (e.g., in Europe, Asia, and two major airports in the US), where slots limit the maximum number of flights that can be operated at an airport in a certain time interval (e.g., one hour) and the airlines' slot demands exceed the available number of slots throughout the day. ${ }^{3}$ Especially in the case traffic volumes. On the other hand, capacity shortages lead to positive traffic delays at congested airports.

${ }^{2}$ The growing importance of aircraft leasing arrangements may gradually increase schedule and fleet planning flexibilities but is unlikely to fully eliminate the inflexibilities. This is due, in part, to the fact that in general leasing is costly relative to airlines' purchasing/owning aircraft (e.g., Oum et al., 2000; Allonen, 2013; Vasigh et al., 2015; Bourjade et al., 2017).

${ }^{3}$ Use-it-or-lose-it rules force airlines to use their slots at least 80 percent of the time because otherwise they might not be able to retain them in the future. This may create some flexibility for airlines to change flight numbers even in situations where slot demands exceed slot numbers throughout the day. We thank an anonymous referee for pointing 
of slot-constrained airports, which are common in Europe and Asia, an increase in flight frequencies may be difficult to implement (e.g., Czerny, Verhoef and Zhang, 2015; Czerny, Van den Berg and Verhoef, 2016). London Heathrow and Hong Kong International Airport can serve as examples. But, it is not generally true (e.g., most airports in the US are not slot-constrained). This is relevant because frequencies determine service quality in two ways: First, an increase in frequency can reduce schedule delays, which measure the extent of whether passengers can travel at their preferred times (e.g., Douglas and Miller, 1974; Brueckner, 2004 and 2010). Second, an increase in frequency can increase congestion in the case of scarce runway capacity. Furthermore, while airline fares often change on a daily basis, flight schedules typically hold for a minimum of half a year. Thus, airlines may choose flight frequencies in order to strategically influence competition at the (subsequent) pricing stage. For example, Brueckner and Flores-Fillol (2007) used specific functional forms to analyze an airline duopoly and showed that frequencies are lower under a sequential structure than in a situation where prices and frequencies are chosen simultaneously when airports are uncongested. This indicates that strategic incentives play a role for frequency decisions indeed. To capture the effect of airport charges structures on service quality and the potential for strategic frequency supply, therefore it is also useful to consider a sequential structure where carriers choose frequencies before fares.

The present study compares the carriers' and the social viewpoints on the mix of per-passenger and per-flight based airport charges under airport cost recovery and with oligopolistic airline markets. ${ }^{4}$ To clearly derive the roles of strategic frequency choices and congestion, it distinguishes between slot-constrained airports where flight frequencies are fully determined by slot numbers (leading to fixed frequencies) and airports where runway allocation is based on the first-come-first-serve principle (leading to endogenous frequencies). The fixed frequencies scenario is discussed in Section 3, where we show that positive per-passenger charges can be used to implement the monopoly solution in the carrier market. This is similar to the results derived by Armstrong (1998) and Laffont et al. (1998a) for telecommunication markets. The reason is that aggregate revenues can approach monopoly revenues by an increase in the customer-related infrastructure charges and, thus, marginal carrier costs. If the corresponding increase comes together with a reduction in other infrastructure costs, e.g., per-flight charges in the case of airports, or matched by an increase in own infrastructure revenues, e.g., in the case of complementary telecommunication networks, marginal infrastructure charges can be used as a strategic device to reach the monopoly solution. This indicates that the current changes in airport charges structures should be critically reviewed at airports where flight frequencies are pre-determined by airport slots.

Sections 4 and 5 consider endogenous frequencies with and without congestion externalities, rethis out to us.

${ }^{4}$ Strict airport cost recovery is considered because in almost all scenarios considered in this paper, the airport cost recovery constraint will be strictly binding from the carriers' and the social viewpoints. 
spectively. The separate discussion of congestion effects is used to add complexity gradually, and to clearly identify the role of congestion for the airlines' preferred airport charges structures. Note that a separate consideration of congestion effects is not necessarily needed in the case with fixed frequencies discussed in Section 3. This is because fixed frequencies are associated with fixed congestion levels when congestion is caused by scarce runway capacity, which means that congestion levels are independent of airport charges structures and therefore irrelevant for the evaluation of airport charges structures.

Frequency effects are indeed crucial for the evaluation of airport charges structures. Section 4 shows that carriers have an incentive to strategically reduce frequency supply in order to soften competition in the pricing stage, which leads to a prisoner's dilemma situation for carriers and reduces social welfare. ${ }^{5}$ Both carriers and the social maximizer can then mitigate the too low incentives for frequency supply by the use of a positive per-passenger charges and the corresponding reduced per-flight charges relative to a situation where airport infrastructure revenues are fully based on per-flight charges. In effect, we show that a necessary condition for the carriers' and the social viewpoints to be in line is that carriers have a preference for per-flight subsidies (which does not necessarily imply negative per-flight charges but rather per-flight charges that are below the airport's per-flight cost). The current move towards positive per-passenger airport charges and reduced flight-related airport charges therefore must not be of concern to policy makers at airports where frequencies are determined by carriers and not by slot constraints. This is in line with the policy recommendation (i.e., policy makers must not be concerned by current changes in airport charges structures) that has been derived by Czerny and Zhang (2015a) for the case of a monopoly carrier.

Congestion effects are important for the evaluation of airport charges structures, too. In this respect, the present study deviates from the results derived by Czerny and Zhang (2015a), who showed that the relationship between the monopoly carrier's and the social viewpoints are independent of the presence of congestion effects. More specifically, if the allocation of scarce runway capacity is based on the first-come-first-serve principle, frequency supply can be excessive for two reasons: (i) carriers internalize only a portion of the congestion costs imposed on carriers and passengers; and (ii) carriers may be able to soften competition in the pricing stage by increasing frequency supply. ${ }^{6}$ For this constellation, it is therefore difficult to derive general policy recommendations because there are strategic forces that support under- and over-supply of frequencies from the carriers' and the social viewpoints.

This paper contributes to several strands of the literature. The first is to the literature on airport pricing, which focuses typically on congestion pricing (and the pricing of airport concession services)

\footnotetext{
${ }^{5}$ According to Fudenberg and Tirole (1984)'s taxonomy, the carriers' strategic reduction of frequency supply may be characterized as a "puppy dog" strategy

${ }^{6}$ According to Fudenberg and Tirole (1984)'s taxonomy, the carriers' strategic increase of frequency supply may be characterized as a "fat cat"strategy
} 
based on passenger-related charges. ${ }^{7}$ Silva and Verhoef (2013) is an exception, and they found that per-flight charges should be used to internalize runway congestion externalities, while the per-passenger subsidies should be used to correct airline market power. Per-passenger subsidies of the form considered by Silva and Verhoef can lead to high airport deficits, which usually are not supported by governments. To our knowledge, the present paper together with the paper by Czerny and Zhang (2015a) are the first studies to evaluate, from both the carrier's and the social viewpoints, the mix of marginal and fixed infrastructure charges under infrastructure cost recovery.

The present paper is closely related to the literature on the strategic use of access charges for the manipulation of oligopolistic competition downstream (e.g., Armstrong, 1998; Laffont et al., 1998a, 1998b). Here, the contribution is to show that similar mechanisms to the ones discussed for telecommunication are relevant for transport. A further contribution is to show that airline agreements on airport charges structures can be used to mitigate strategic undersupply of flight frequencies (or, strategic oversupply of flight frequencies) and congestion externalities. The paper also adds to the discussion about whether long-term airport-airline agreements can lead to socially desired outcomes. For example, Bush and Starkie (2014) mention that such long-term agreements may serve as a substitute for the economic regulation of airport aeronautical charges. Our results for fixed frequencies show that airport-airline agreements may not always be socially desirable (Czerny, Guiomard and Zhang, 2016). Finally, because schedule delays can be considered as a service-quality dimension, this paper adds to the literature on quality supplies, which was introduced by the seminal papers of Spence (1975) and Sheshinski (1976).

\section{Basic Model}

The supply side is described first. There is an upstream, uncongested airport that provides an essential input (e.g., runway and terminal capacity) to two symmetric downstream carriers that provide differentiated services. ${ }^{8}$ Airport charges are of two types: a per-passenger charge, denoted $\tau_{q}$, and a charge per flight (e.g., arrival and departure of an aircraft) denoted $\tau_{f}$; both of which are charged to the carriers. Notice, since the payment of airport charges is separable from other social costs, the assumption that the per-passenger charge is levied to the carrier (not passengers) is without loss of generality. ${ }^{9}$ No restrictions are imposed on the sign of the infrastructure charges $\tau_{q}$ and $\tau_{f}$. However, we will mainly concentrate on scenarios where the airport can fully reover all its costs including possible subsidy payments in the form of negative markups on operating costs. Denote the carriers'

\footnotetext{
${ }^{7}$ See Zhang and Czerny (2012) for a survey paper on airport congestion pricing and airport concession revenues.

${ }^{8} \mathrm{An}$ example that concentrates on the more general case of an arbitrary number of $n \geq 1$ carriers is discussed in Appendix B.1.

${ }^{9} \mathrm{ICAO}$ (2012) proposes that airport passenger-service charges should be levied through aircraft operators rather than passengers for the purpose of increasing the efficiency of collecting airport charges (noting that there are much less carriers than passengers).
} 
passenger quantities as $q_{1}$ and $q_{2}$, frequencies as $f_{1}$ and $f_{2}$, and fares as $p_{1}$ and $p_{2}$ for carriers 1 and 2 , respectively. Aircraft are all of the same size with a non-binding maximum capacity. ${ }^{10}$ This leads to an infrastructure (airport) revenue of $\sum_{i=1,2}\left(\tau_{q} q_{i}+\tau_{f} f_{i}\right)$. Letting $F(>0)$ denote the fixed airport costs (e.g., the capital costs of terminal and runway capacity) and normalizing the airport's per-passenger and per-flight costs to zero, airport profit, denoted $\Pi$, can be written as $\Pi \equiv \sum_{i=1,2}\left(\tau_{q} q_{i}+\tau_{f} f_{i}\right)-F$. In this scenario where the airport operating costs are normalized to zero, negative infrastructure charges may actually have the interpretation of positive charges that are below marginal operating costs producing a negative markup on costs. The carriers' per-passenger costs are normalized to zero as well (besides the per-passenger charge), whilst the carriers' per-flight costs are denoted as $c(>0) .{ }^{11}$ The individual carrier profits, denote $\pi_{i}$, can then be written as $\pi_{i} \equiv\left(p_{i}-\tau_{q}\right) q_{i}-\left(\tau_{f}+c\right) f_{i}$, with $i=1,2$, where the first term on the right-hand side is the carrier's revenue less the per-passenger based payment to the airport and the second part is the flight-related costs including the flight-based payment to the airport. The aggregate carrier profit, denoted as $\pi$, is written as $\pi \equiv \pi_{1}+\pi_{2}$.

Turning to the demand side (subscripts indicate partial derivatives; e.g., $\partial f\left(x_{1}, x_{2}\right) / \partial x_{i} \equiv f_{i}$ and $\left.\partial^{2} f / \partial x_{i} \partial x_{j} \equiv f_{i j}\right):$

Assumption 1 Let $B$ denote (gross) travel benefits with $B \equiv B\left(q_{1}, q_{2}\right), B_{i}>0$ and $B_{i i}<B_{i j}<0$, for $i=1,2$ and $j \neq i .^{12}$

This assumption implies that the benefits are strictly concave in the individual passenger quantities, and that individual passenger quantities are imperfect substitutes.

The generalized passenger costs ("generalized prices") are composed of fares $p_{i}$ and the perpassenger "schedule delay costs," with the latter, denoted as $\Gamma$, being the costs a passenger incurs for the time between the passenger's desired departure and the actual departure time. ${ }^{13}$ Letting $\eta_{i}$ denote carrier $i$ 's generalized price, it holds that $\eta_{i} \equiv p_{i}+\Gamma$, where the passengers' schedule delays depend on the flight frequency of the individual carrier, i.e., $\Gamma \equiv \Gamma\left(f_{i}\right) .{ }^{14}$ Assume that schedule delay costs are a strictly convex function in frequency, that is $\Gamma^{\prime}<0$ and $\Gamma^{\prime \prime}>0$. Passenger demands for carriers 1 and 2 are determined by the equilibrium conditions $B_{1}=\eta_{1}$ and $B_{2}=\eta_{2}$. Inverting the equilibrium

\footnotetext{
${ }^{10}$ Letting $\bar{q}$ denote the maximum passenger quantity per flight, load factors can be derived as $\left(q_{i} / f_{i}\right) / \bar{q}$, where $q_{i} / f_{i}$ is the quantity of passengers per flight with $\bar{q}>\left(q_{i} / f_{i}\right)$ by assumption.

${ }^{11}$ As noted in, e.g., Brander and Zhang (1990), once a flight is committed to service, costs per passenger are usually rather small.

${ }^{12}$ Here and in the remainder of the paper, if $i$ and $j$ appear in the same expression, it is to be understood that $j \neq i$.

${ }^{13} \mathrm{We}$ assume, as is common in the literature, that consumers are able to place a monetary value on non-price service attributes.

${ }^{14}$ According to Douglas and Miller (1974), the schedule delay may be decomposed into "frequency delay" and "stochastic delay." The former refers to the difference between one's desired departure time and the closest scheduled departure by the airline, whereas the latter is delay that can be caused by excess demand for one's preferred flight(s). Both types of delays can depend on flight frequency. However, stochastic delays can also be caused by flight cancellations or departure delays due to bad weather or other external factors.
} 
conditions yields demands denoted as $D_{i}$, with $D_{i} \equiv D_{i}\left(\eta_{1}, \eta_{2}\right) \cdot{ }^{15}$ Cramer's rule can be applied to the equilibrium conditions, $B_{1}=\eta_{1}$ and $B_{2}=\eta_{2}$, to derive the following properties of the demands where $D\left(=D_{1}+D_{2}\right)$ denotes the aggregate demand (all the proofs of lemmas and propositions are relegated to Appendix A):

Lemma 1 The carriers' own demands are decreasing in the own fare and increasing in the rival's fare (i.e., $\partial D_{i} / \partial \eta_{i}=B_{j j} / \Psi<0$ and $\partial D_{i} / \partial \eta_{j}=-B_{j i} / \Psi>0$ with $\Psi \equiv B_{11} B_{22}-\left(B_{21}\right)^{2}$ for $j \neq i$ ), while the aggregate demand is decreasing in fares (i.e., $\left.\partial D / \partial \eta_{i}=\left(B_{j j}-B_{j i}\right) / \Psi<0\right)$.

We consider a three-stage game. In the first stage, the per-passenger and per-flight charges are determined so as to ensure airport cost recovery. The first stage is analyzed from the carriers' and the social viewpoints in order to identify their incentives with respect to airport charges structures. The analysis of the carriers' view is based on the observation that airlines seem to be able to agree on a joint position on airport charges structures, which they then promote via their trade organization, IATA. The question remains whether their view is consistent with the view of a social optimizer who cares about passengers as well as carriers. More specifically, a social optimizer is concerned about social welfare, denoted $W$ with $W \equiv B-\sum_{i=1,2}\left(\Gamma\left(f_{i}\right) q_{i}+c f_{i}\right)-F$, which is the sum of aggregate profits $\pi$ and consumer surplus, denoted $C S$ with $C S \equiv B-\sum_{i=1,2} \eta_{i} q_{i}$, while carriers are only concerned about aggregate profits $\pi$.

Two variations of the second stage are considered. The first variation considers the carriers' frequencies as given (the three-stage game essentially collapses to a two-stage game). This specification aims to capture that it is easier, especially in the short run, for carriers to change fares than to change aircraft fleet and schedules (e.g., Brueckner and Luo, 2014). It further captures that slot constraints can impose an upper limit on flight quantities in the case of a sufficiently high passenger demand as is the case at many European and Asian airports. The second variation assumes that carriers simultaneously and independently choose frequencies. This captures that carriers can change their fight frequencies in the longer run, which is especially true for airports where slot constraints are absent and runway allocation is based on the first-come-first-serve principle as is true for most US airports. These two variations are examined in Sections 3 and 4, respectively. In the third stage, carriers simultaneously and independently choose fares.

\section{$3 \quad$ Fixed Frequencies}

This section considers a situation where frequencies are fixed. To analyze the viewpoints of carriers and the social maximizer under these conditions, we impose, in this section, symmetry in the sense

\footnotetext{
${ }^{15}$ The Jacobian of the demand system $\left(D_{1}\left(\eta_{1}, \eta_{2}\right), D_{2}\left(\eta_{1}, \eta_{2}\right)\right)$ is negative definite, which means that the system of demands is invertible (e.g., Vives, 1999).
} 
that frequencies are the same for carriers 1 and 2 and given by $\bar{f}$, i.e., $f_{1}=f_{2}=\bar{f}$. The carriers' behaviors in terms of fares are determined by the first-order conditions $\partial \pi_{i} / \partial p_{i}=0$, which can be written as $D_{i}+\left(p_{i}-\tau_{q}\right) \cdot \partial D_{i} / \partial \eta_{i}=0$. We employ the following assumption to justify this approach:

\section{Assumption 2 Demand functions satisfy conditions (i)}

$$
\frac{\partial D_{i}}{\partial \eta_{j}}+\left(p_{i}-\tau_{q}\right) \frac{\partial^{2} D_{i}}{\partial \eta_{i} \partial \eta_{j}}>0
$$

and (ii)

$$
\frac{\partial D_{i}}{\partial \eta_{i}}+\frac{\partial D_{i}}{\partial \eta_{j}}+\left(p_{i}-\tau_{q}\right)\left(\frac{\partial^{2} D_{i}}{\partial \eta_{i}^{2}}+\frac{\partial^{2} D_{i}}{\partial \eta_{i} \partial \eta_{j}}\right)<0
$$

Part (i) of Assumption 2 ensures that $\partial^{2} \pi_{i} / \partial p_{i} \partial p_{j}>0$, which implies that fares are strategic complements and hence the best response functions are positively sloped in the fares space. This is a standard assumption in Bertrand competition. ${ }^{16}$ Parts (i) and (ii) ensure that the second-order conditions, $\partial^{2} \pi_{i} / \partial p_{i}^{2}<0$, and the contraction conditions, $\partial^{2} \pi_{i} / \partial p_{i}^{2}+\left|\partial^{2} \pi_{i} / \partial p_{i} \partial p_{j}\right|<0$, are satisfied, which together ensure the existence of best responses in fares and a unique Bertrand-Nash equilibrium. ${ }^{17}$

Strategic complementarity implies that the third-stage Bertrand game is supermodular. A game can be called supermodular if the increment in a player's payoff due to an increase in its strategy variable is increasing in the strategy variable of any of the other players (e.g., Topkis, 1998; Vives, 1999). The property of supermodularity can be used to derive the comparative static relationships between the equilibrium fares and per-passenger charge $\tau_{q}$. More specifically, the partial derivatives $\partial \pi_{i} / \partial p_{i}$ are increasing in $\tau_{q}$, which implies that best responses in terms of fares are increasing in the per-passenger charge: ${ }^{18}$

Lemma 2 An increase in the per-passenger charge, $\tau_{q}$, increases the equilibrium fares.

An increase in the airport per-passenger charge raises the airlines' marginal costs. It is therefore intuitive that an increase in the per-passenger charge raises their equilibrium fares.

To derive the profit-maximizing airport charges structure from the carriers' viewpoint, it is useful to understand that any reduction in per-flight payments to the airport would increase the carriers' profits. The airport cost-recovery constraint therefore is strictly binding from the carriers' viewpoint, i.e., $\tau_{q} q+\tau_{f} 2 \bar{f}-F=0$ in the carriers' optimum. Using symmetry, equilibrium fares can be written as $p_{1}=p_{2}=p$. This together with the airport cost-recovery constraint leads to aggregate carrier profits $\pi=p D-2 c \bar{f}-F$. The optimal per-passenger charge from the carriers' viewpoint is determined by the

\footnotetext{
${ }^{16}$ The concept of strategic complementarity has been developed by Bulow et al. (1985). Vives (1999) provides a discussion about the possibilities of prices being strategic complements or substitutes in the case of product differentiation.

${ }^{17}$ See Vives (1999) for a discussion of the contraction condition in the context of a Bertrand oligopoly with product differentiation.

${ }^{18}$ This follows from Topkis (1998), Theorem 4.2.2. Cramer's rule can also be applied to prove this result as is shown in Appendix A.
} 
first-order condition $\partial \pi / \partial \tau_{q}=0$, which leads to $(D+p \cdot \partial D / \partial p) \cdot \partial p / \partial \tau_{q}=0$. Since $\partial p / \partial \tau_{q}$ is strictly positive by Lemma 2, the per-passenger charge should be chosen such that it induces maximization of aggregate carrier revenues, which is just the same as the monopoly solution. This means that, for fixed frequencies, carriers can use a strictly positive per-passenger charge to implement the monopoly solution downstream.

Carriers deviate from the monopoly solution when the per-passenger charge is too low because their choice of fares ignores that there is a positive externality in the sense that an increase of the own fare increases the rival's profit by amount $p \cdot \partial D_{j} / \partial \eta_{i}$ (in equilibrium). To achieve the monopoly solution, a strictly positive per-passenger charge can therefore be used to internalize the effect of own fares on the rival's profit:

Proposition 1 For given frequencies $f_{1}=f_{2}=\bar{f}$ and strict airport cost recovery, a strictly positive per-passenger charge, $\tau_{q}$, equal to $-p_{j}\left(\partial D_{j} / \partial \eta_{i}\right) /\left(\partial D_{i} / \partial \eta_{i}\right)$ evaluated at the monopoly carrier solution, can be used to implement the monopoly fares.

This demonstrates that oligopoly carriers may indeed have a strong incentive to lobby for a positive per-passenger charge when frequencies are exogenously fixed. In effect, the charges structure may serve as a coordination device for carriers to raise the fare and implement the monopoly outcome. Note, however, that it is possible that the revenue generated for the airport from the carriers' preferred per-passenger charges may be more than sufficient to cover the airport's costs. In this case, the only way the airport could make zero profits would be to give a subsidy to flights in the form of negative markups. This may be difficult to implement in practice and means that carriers could only approximately reach the monopoly outcome by the manipulation of airport charges structures in such cases.

Proposition 1 complements the results derived by Armstrong (1998) and Laffont et al. (1998a), who concentrated on telecommunication companies. They showed that firms can implement the monopoly solution by the choice of "common reciprocal infrastructure access charges", i.e., access charges that are the same for the own and the rivals' use of own infrastructure, to their infrastructure networks to each other. One important feature of their framework is that firms are vertically integrated and therefore directly choose their access charges. On the other hand, in our framework carriers may be able to indirectly influence infrastructure charges structures by proposing a change in the perpassenger and per-flight based charges to the airport operator, which leaves the airport indifferent because airport profit remains unchanged. The carriers' approach functions for all values of $F$, as long as monopoly profit downstream is greater than $F$ and is therefore independent of whether airport profits are zero, positive or, possibly, negative.

Armstrong (1998) and Laffont et al. (1998a) further show that the firms' preferred infrastructure access charges are excessive from the social viewpoint, and the same is true for the carriers' preferred 
airport charges structure in our scenario when frequencies are fixed. To see this, note that the welfaremaximizing fares are determined by marginal passenger costs, which are normalized to zero. In the welfare optimum carrier revenues are therefore zero as well, which means that carriers are unable to finance airports through per-flight based charges under these first-best conditions. So, the second-best optimum is the minimal per-passenger charge conditional on airport cost recovery, which is lower than the per-passenger charge that implements the monopoly solution downstream as long as the airport fixed costs are lower than the monopoly profit downstream. Thus, the carriers' optimal per-passenger charge is excessive from the social viewpoint, which provides a clear intuition for the conflicting views on per-passenger charges when frequencies are considered as given and indicates the need for policy intervention. This result can be extended to the case of an arbitrary number of carriers as is shown in Appendix B.1.

Altogether, this shows that the results derived by Czerny and Zhang (2015a) on the use of a zero per-flight charge as a signal for the potential common interests of carriers and the social optimizer is sensitive with respect to carrier market structures. More specifically, it seems unlikely to hold when carrier markets are oligopolistic and, at the same time, frequencies are fixed by circumstances discussed in the introduction and the previous section. Still, the assumption of fixed frequencies is a strong assumption in many contexts and especially for the US where runway allocation is largely based on the first-come-first-serve principle.

\section{Endogenous Frequencies}

The following analysis assumes that carriers independently and simultaneously choose frequency supply in the second stage, while fares are determined in the third stage. As before, we solve the game by backward induction for carriers and the social optimizer.

\subsection{Carriers' viewpoint}

Third-stage analysis. To understand the carriers' and the social viewpoints on airport charges structures, it is crucial to understand how frequencies affect the pricing game in the third stage. The analysis of the third stage is therefore separated in two parts, where the first part concentrates on best respones in terms of fares, and the second part concentrates on equilibrium fares.

The best responses of the two carriers are implicitly determined by the first-order conditions $\partial \pi_{i} / \partial p_{i}=0$. To derive the effect of own frequency supply on best responses, the implicit function theorem is separately applied to the own and the rival's first-order conditions for best responses. This yields:

Lemma 3 (i) The carriers' best responses in terms of fares are increasing in own frequencies, while the own generalized prices are decreasing in own frequencies. (ii) The rival's best responses in terms 
of fares and, thus, its generalized prices are decreasing in own frequencies.

The increase in the fare responses mentioned in part (i) can be explained by the fact that an increase in own frequency supply increases own demands. But, the increase in the fare responses is dominated by the reduction in schedule delay costs in the sense that the own generalized price is decreasing in the own frequency supply. Because an increase in own frequency supply reduces the own generalized price and fares are strategic complements, this reduces the rival's best response in terms of the fares. Thus, the increase in individual frequency supply strengthens competition in the sense that it induces a more aggressive pricing behavior of the rival carrier.

The effect of frequency supply on equilibrium fares can be derived by totally (and simultaneously) differentiating the first-order conditions $\partial \pi_{1} / \partial p_{1}=0$ and $\partial \pi_{2} / \partial p_{2}=0$ with respect to fares $p_{i}$ and $p_{j}$ and frequency $f_{i}$, and by applying Cramer's rule. This leads to:

Lemma 4 (i) An increase in own frequency supply increases the own equilibrium fare and reduces the rival's equilibrium fare. (ii) An increase in frequencies $\bar{f}$ with $f_{1}=f_{2}=\bar{f}$ increases the equilibrium fares.

Part (i) can be explained by the fact that an increase in own frequency supply increases own demand and strengthens competition from the rival's viewpoint. Part (ii) is true because an increase in the overall level of frequency supplies increases demands for carriers 1 and 2, while the relative competitiveness of carriers remains the same.

Second-stage analysis. Turning to the frequency choices in stage two, the equilibrium frequencies are implicitly determined by the first-order conditions $\partial \pi_{i} / \partial f_{i}=0 .{ }^{19}$ Using the first-order conditions for fares in the third stage, the first-order conditions for frequency supplies can be written as

$$
\left(p_{i}-\tau_{q}\right) \frac{\partial D_{i}}{\partial \eta_{j}} \frac{\partial p_{j}}{\partial f_{i}}-D_{i} \Gamma^{\prime}-\left(\tau_{f}+c\right)=0 .
$$

The first term on the left-hand side captures the effect of own frequency supplies on the rival's equilibrium fare. This term is negative because an increase in own frequency reduces the rival's equilibrium fare by Lemma 4 (i). The second term captures the reduction in the own passengers' schedule delays associated with an increase in own frequencies. This term is positive. The third term is the negative marginal frequency costs, which is the negative sum of the airport per-flight charge and per-flight cost $c$.

To identify the effect of the sequential game structure, suppose that fares and frequencies are chosen simultaneously. Then, the first term on the left-hand side vanishes because the first-order

\footnotetext{
${ }^{19}$ To ensure the existence of a unique equilibrium in frequency choices, it is assumed, it is assumed that profits are concave in own frequency supplies, $\partial^{2} \pi_{i} / \partial f_{i}^{2}<0$, and that the contraction conditions, $\partial^{2} \pi_{i} / \partial f_{i}^{2}+\left|\partial^{2} \pi_{i} / \partial f_{i} \partial f_{j}\right|<0$, are satisfied (this is similar to Assumption 2, which guarantees the existence of a unique Bertrand-Nash equilibrium in the pricing stage). A numerical example that satisfies this condition is provided in Appendix B.2.
} 
conditions for frequencies would be derived for given fares. And in this case frequencies would be chosen in a way which ensures that carriers increase frequencies as long as the marginal reduction in schedule delay costs is at least as high as the marginal frequency costs. Thus, carriers fully internalize changes in the schedule delay costs of own passengers. This is because the carriers' generalized prices are the same for all passengers and given by the sum of the fares and schedule delay costs, which ensures that carriers can internalize any reduction in schedule delays by an increase in fares. The carriers' rationale for the choice of frequencies changes under a sequential game structure, because the first term on the left-hand side of first-order condition (3) is negative.

The above discussion leads to:

Proposition 2 With endogenous frequency supplies, carriers' frequencies are strategically reduced in the sense that the reduction in schedule delays associated with marginal increases in individual frequencies exceeds the marginal frequency costs (i.e., $-D_{i} \Gamma^{\prime}-\left(\tau_{f}+c\right)>0$ ) in equilibrium.

Recall that by Lemma 4 (i), frequency supply strengthens competition in the sense that it reduces the rival's fare. Proposition 2 shows that carriers anticipate this pro-competitive effect and strategically reduce frequencies in the second stage. Using Fudenberg and Tirole's (1984) taxonomy, carriers use the puppy-dog strategy in order to soften competition in the third stage. ${ }^{20}$ But as all carriers follow a puppy-dog strategy, this by Lemma 4 (ii) reduces the level of fares and aggregate profits. In effect, carriers are caught in a classic prisoner's dilemma situation.

First-stage analysis. In order to derive the optimal airport-charges structure from the carriers' viewpoint (and the social viewpoint), it is useful to understand the effects of airport charges on equilibrium frequencies. More specifically, an increase in the per-flight charges increases per-flight costs, which leads to:

Lemma 5 An increase in the per-flight charges reduces the carriers' equilibrium frequency supplies.

Different combinations of per-passenger and per-flight based charges can ensure airport cost recovery. Following Czerny and Zhang (2015a), who consider a monopoly carrier, we concentrate on those combinations of per-passenger and per-flight based charges where an increase in the per-passenger charge is associated with a reduction in the per-flight charge, i.e., $d \tau_{f} / d \tau_{q}<0$. For an intuition, consider the zero airport-profit contour in the $\tau_{q^{-}} \tau_{f}$-space, which may be described by an ellipse:

\footnotetext{
${ }^{20}$ Our model is not directly comparable with the setting analyzed by Fudenberg and Tirole (1984), because fares and generalized prices are identical in their setting, while the two differ in our setting. Thus, if fares are strategic complements, an increase in the own fare increases the rival's fare in their setting, while an increase in the own fare may be associated with a reduced own generalized and a reduced rival's generalized price in our setting.
} 
Because monopoly profits downstream will always be increased by a reduction in one of these charges, only the downward sloping part of the contour is relevant for carriers, where $d \tau_{f} / d \tau_{q}<0$ holds true. ${ }^{21}$

We further follow Czerny and Zhang (2015a) by distinguishing between the frequency effect and the fare effect of a change in the airport charges structure. The frequency effect is denoted $\Delta_{\bar{f}}$ and measures how an increase in the per-passenger charge changes the carriers' individual equilibrium flight frequencies. This effect can be positive or negative because an increase in $\tau_{q}$ may reduce frequency as it reduces the passenger quantity, while it indirectly increases frequency as it reduces the per-flight charge. The fare effect is denoted $\Delta_{p}$ and measures how an increase in the per-passenger charge directly changes the equilibrium fare and indirectly changes the fare through changes in frequency supply. This effect can also be positive or negative in sign, because $\Delta_{\bar{f}}$ can be positive or negative in sign. Frequency and fare effects are hence both ambiguous in sign and can be written as

$$
\Delta_{\bar{f}} \equiv \frac{\partial \bar{f}}{\partial \tau_{q}}+\frac{\partial \bar{f}}{\partial \tau_{f}} \frac{\partial \tau_{f}}{\partial \tau_{q}} \text { and } \Delta_{p} \equiv \frac{\partial p}{\partial \tau_{q}}+\frac{\partial p}{\partial \bar{f}} \Delta_{\bar{f}}
$$

respectively.

Assume that the optimal per-passenger charge from the carriers' viewpoint is determined by the first-order condition $\partial \pi / \partial \tau_{q}=0$. Using symmetry, this condition can be written as

$$
\Delta_{p} D_{i}+p \frac{\partial D_{i}}{\partial \eta_{i}} \underbrace{\left(\Delta_{p}+\Delta_{\bar{f}} \Gamma^{\prime}\right)}_{\equiv \Delta_{\eta}}-\Delta_{\bar{f}} c=0
$$

The first two terms on the left-hand side show the change in individual revenues associated with a marginal increase in the per-passenger charge. This change is composed of (i) the change in individual revenues associated with the change in the equilibrium fares, $\Delta_{p}$, and (ii) the change in individual revenues associated with the change in demands caused by a change in the equilibrium generalized prices, $\Delta_{\eta} \equiv \Delta_{p}+\Delta_{\bar{f}} \Gamma^{\prime}$. The third term shows the increase in individual frequency costs associated with a marginal increase in the per-passenger charge. Then, the per-passenger charge maximizes aggregate profit if these revenue and cost effects are equal in absolute values. Aggregate profit is optimized because frequency and fare effects $\Delta_{\bar{f}}$ and $\Delta_{p}$, respectively, refer to changes in equilibrium values of fares and frequencies (and not just individual changes in fares and frequencies).

Recall that carriers strategically reduce frequencies, which reduces aggregate profit. It seems natural that carriers will use airport charges structures to overcome this strategic behavior. And, they can do this by the use of a positive per-passenger charge, which reduces the per-flight charge relative to a situation where airport infrastructure revenues fully rely on per-flight charges. Appendix B.2 is used to illustrate this insight numerically and shows that a change in infrastructure charges can partly eliminate strategic frequency reductions. Altogether, this provides another explanation

\footnotetext{
${ }^{21}$ Choo (2014) provides empirical evidence for the negative relationship between per-passenger and per-flight airport charges.
} 
why carriers may be interested in positive per-passenger charges: Carriers benefit from low per-flight charges because this mitigates the profit reductions associated with strategic frequency reductions.

Note that the optimality condition in (5) is similar to the one for a monopoly carrier derived by Czerny and Zhang (2015a). However, one difference is that the present framework captures two differentiated markets (indicated by indices $i$ ), while Czerny and Zhang concentrated on a single market. Another difference is that the sequential game structure plays a role for oligopolistic markets, while it has no effect on the monopoly carrier's behavior. The policy lessons derived by Czerny and Zhang (2015a) can therefore not simply be applied to oligopolistic markets as will be shown in the following sub-section.

\subsection{Carriers' versus social viewpoints}

First we show that the airport cost-recovery constraint is also binding from the social viewpoint. Then, we compare the carriers' and the social viewpoints on airport charges structures.

Assume that the welfare-optimal frequencies are determined by the first-order condition $\partial W / \partial f_{i}=$ 0 . Substituting fares by zero (i.e., the welfare-optimal fare $p^{*}$ ), this condition simplifies to $-D_{i} \Gamma^{\prime}-c=0$ and shows that frequencies are welfare-optimal if marginal reductions in schedule delays are equal to marginal frequency costs. Comparing this condition with the first-order condition in (3) reveals that the carrier's frequency choice is optimal from the social viewpoint if the strategic choice of frequency supply in stage two would be absent (i.e., when frequency supply and prices are chosen simultaneously). It is useful to understand that the frequency supply can be considered as a quality dimension (high frequency reduces passenger schedule delays) and thus the finding that the carriers' frequency supply can be optimal from the social viewpoint is anticipated by the analyses of Spence (1975) and Sheshinski (1976). They showed that the firms' quality supply is optimal from the social viewpoint if the quality valuation of the marginal customer is representative for all customers because these conditions ensure the full internalization of benefits associated with quality gains. ${ }^{22}$ Since time valuations are assumed to be the same for all passengers, the marginal passenger's time valuations are indeed representative, and therefore the carriers' frequency choices are optimal from the social viewpoint when passenger quantities are given and strategic frequency considerations are absent. ${ }^{23}$ But, the existence of the puppy-dog strategy implies that a negative per-flight charge is required to achieve the first-best result in terms of frequencies. Thus, the carrier supplies in terms of both passenger quantities and frequencies must be subsidized to achieve the first-best result under these conditions. The airport cost-recovery

\footnotetext{
${ }^{22}$ Spence (1975) and Sheshinski (1976) concentrate on monopoly firms. But, their main result on the relative incentives for quality supply from the firm's and the social viewpoints extend to the oligopoly case.

${ }^{23}$ In the context of a monopoly airline market, Czerny and Zhang (2015a) consider scenarios where the carrier's incentive to increase frequency supply is reduced by the existence of business passengers who exhibit a high time valuation relative to leisure passengers and where marginal time valuations are low relative to average time valuations.
} 
constraint is therefore strictly binding from the carriers' and the social viewpoints. ${ }^{24}$

To analyze the distinct views on per-passenger charges from the carriers' and the social viewpoints, consider the unifying objective $V \equiv \pi+\phi C S$, where $\phi$ is called the viewpoint parameter with $\phi \in[0,1]$. For $\phi=0$, the objective is maximization of aggregate carrier profit, whilst it is welfare maximization for $\phi=1$. This objective function has already anticipated that the airport cost-recovery constraint is strictly binding from the carriers' and the social viewpoints because airport profit is assumed to be zero.

The distinct feature between the carriers' and the social viewpoints is that the social optimizer also cares about consumers. The change in consumer surplus associated with the change in the perpassenger charge conditional on airport cost recovery can be written as the derivative $\partial C S\left(\eta_{1}, \eta_{2}\right) / \partial \tau_{q}=$ $-\Delta_{\eta} D$, where the right-hand side is the product of the passenger quantity with the negative of the change in generalized prices associated with a marginal change in the per-flight charges. This derivative can then be used to write the first-order condition for the optimization of the unifying objective $V$ as

$$
\Delta_{p} D_{i}-\Delta_{\bar{f}} c+\Delta_{\eta}\left(p \frac{\partial D_{i}}{\partial \eta_{i}}-\phi D_{i}\right)=0
$$

The left-hand side implies that carriers' and the social viewpoints will lead to identical airport charges structures only if $\Delta_{\eta}=0$ is satisfied in the carriers' and the social optimum. Using $\Delta_{\eta}=0$ (i.e., $\left.\Delta_{p}=-\Delta_{f} \Gamma^{\prime}\right)$ the first two terms on the left-hand side can be written as $\Delta_{f}\left(-D_{i} \Gamma^{\prime}-c\right)$, which can be zero only if flights are subsidized in optimum because carriers employ the puppy-dog strategy. This leads to:

Proposition 3 With endogenous frequency supplies, per-flight subsidies are a necessary condition for the carriers' and the socially optimal per-passenger and per-flight based airport charges to be identical.

Two insights can be derived from this proposition. First, it can be used to reveal the effect of oligopolistic carrier markets on the optimality of airport charges structures from the carriers' and the social viewpoints. Czerny and Zhang (2015a) consider a monopoly carrier and show that a necessary and sufficient condition for the carrier's and the social viewpoints to be identical is that the optimal per-flight charge is zero. This is different in an oligopoly scenario, where the corresponding necessary condition involves per-flight subsidies. Second, the fact that carriers lobby for high per-passenger charges may indeed indicate that the carriers' and the social viewpoints are consistent because positive per-passenger charges allow airports to achieve cost recovery with low per-flight charges relative to a situation where revenues fully rely on per-flight charges.

\footnotetext{
${ }^{24}$ Brueckner and Flores-Fillol (2007) show that the carriers' frequency supply can be too low from the social viewpoint when frequencies and fares are chosen sequentially. However, their analysis is based on specific functional forms and they do not relate their finding to the carriers' strategic incentives for the manipulation of competition in the pricing stage.
} 


\section{Congestion}

Airport congestion due to limited runway capacity has been a major problem in many parts of the world (e.g., Zhang and Czerny, 2012). Some regions, especially, in Asia and Europe, make use of airport slots, which limit the number of vehicles that can be operated at an airport in a certain time interval (e.g., one hour), in order to control congestion. For these airports the results derived in Section 3 may apply, which shows that airlines can use airport charges structures as a device to implement the monopoly market outcome downstream. However, in the US, which is the largest domestic air transport market in the world, the allocation of runway capacity is primarily based on the first-comefirst-serve basis. ${ }^{25}$ Here, congestion can change the results mentioned in Proposition 3. This is because congestion makes it difficult to derive insights about the social benefits of airport charges structures by simply checking the statements of carriers' preferences when carrier markets are oligopolistic and first-come-first-serve is used for runway allocation. ${ }^{26}$

To see this let $f$ denote the aggregate frequency supply, i.e., $f \equiv f_{1}+f_{2}$. Furthermore, assume that the carriers' per-flight operating costs are composed of $c$ and a second element denoted as $\Lambda_{\pi}$ that is increasing in aggregate frequency $f$, i.e., $\Lambda_{\pi} \equiv \Lambda_{\pi}(f)$ with $\Lambda_{\pi}^{\prime}>0$. Congestion is also inconvenient for passengers. To capture this, denote the per passengers' congestion costs as $\Lambda_{q}$ with $\Lambda_{q} \equiv \Lambda_{q}(f)$ and $\Lambda_{q}^{\prime}>0$. This leads to generalized prices $\eta_{i}=p_{i}+\Gamma\left(f_{i}\right)+\Lambda_{q}(f)$, carrier profits $\pi_{i}=\left(p_{i}-\tau_{q}\right) q_{i}-\left(\tau_{f}+c+\Lambda_{\pi}\right) f_{i}$, where $p_{i}=B_{i}-\left(\Gamma+\Lambda_{q}\right)$ in demand equilibrium, and welfare $W=B-\left(\Gamma+\Lambda_{q}\right) q-\left(c+\Lambda_{\pi}\right) f$. Congestion thus has two effects: (i) it increases per-flight operating costs; and (ii) it reduces fares for a given passenger quantity because a congested flight is of lower perceived quality by passengers, which reduces profits, consumer surplus and, hence, welfare.

To understand how congestion changes the carriers' preferences for airport charges structures, it is insightful to consider the first-order condition for frequency choices, $\partial \pi_{i} / \partial f_{i}=0$. Using symmetry, these can be written as

$$
\left(p_{i}-\tau_{q}\right) \frac{\partial D_{i}}{\partial \eta_{j}} \cdot \underbrace{\left(\frac{\partial p_{j}}{\partial f_{i}}+\Lambda_{q}^{\prime}\right)}_{(\mathrm{b})}-\underbrace{\frac{1}{2}\left(D \Lambda_{q}^{\prime}+f \Lambda_{\pi}^{\prime}\right)}_{(\mathrm{a})}-D_{i} \Gamma^{\prime}-\left(\tau_{f}+c+\Lambda_{\pi}\right)=0 .
$$

The bracketed terms indicated by (a) and (b) are two crucial factors for the discussion. The terms in (a) capture that per-flight costs are endogenous and depend on the aggregate number of flights. This is true because differentiating the total congestion costs, $D \Lambda_{q}+f \Lambda_{\pi}$, with respect to $f_{i}$ leads to marginal congestion costs $\Lambda_{\pi}+D \Lambda_{q}^{\prime}+f \Lambda_{\pi}^{\prime}$. Notice that the first part, $\Lambda_{\pi}$, is internalized by carriers

\footnotetext{
${ }^{25}$ JFK and LaGuardia are effectively the only slot controlled airports in the US. Slot controls for Newark airport were dropped in 2016. Reagan National Airport in Washington is slot controlled but demand seems to fall behind capacity (Gillen et al., 2016).

${ }^{26}$ Czerny and Zhang (2015a) demonstrate that it may not be necessary to explicitly model congestion costs when a monopoly carrier is considered. This is because schedule delays can also capture the notion of passenger congestion costs in the sense that they decrease at a declining absolute rate, which can occur due to an increase in runway congestion.
} 
because it forms part of the carriers' per-flight cost, $\tau_{f}+c+\Lambda_{\pi}$. The second and the third parts appear in terms (a) but are evaluated at market share $1 / 2$. This means that carriers internalize only the congestion costs that an additional flight imposes on the own passengers and own flights but ignore the congestion costs imposed on the rival's passengers and flights. That carriers only internalize the congestion they impose on themselves is well known from the literature (e.g., Daniel, 1995; Brueckner, 2002; Zhang and Zhang, 2006), but for the present study it is relevant because in the first stage carriers can use a positive per-flight charge to internalize otherwise uninternalized congestion costs, which increases aggregate carrier profits. Thus, congestion provides an argument which is in favor of a positive per-flight charge when the allocation of runway capacity is based on the first-come-first-serve principle.

Turning to the strategic choice of frequencies brings us to factor (b). With congestion, its sign depends on the sum of two terms, where the first term, $\partial p_{j} / \partial f_{i}$, describes how an increase in own frequency changes the rival's equlibrium fare and the second term how it increases the per-passenger congestion costs, $\Lambda_{q}^{\prime}$, and thus reduces the passengers willingness to pay for flights. The first term is negative in sign: While an increase in own frequency reduces schedule delays of own passengers, it increases the own fare and reduces the rival's fare when congestion effects are absent (Lemma 4). The same is also true with congestion as long as the reduction in schedule delays is greater in absolute values than the increase in passenger congestion costs, i.e., $\Gamma^{\prime}+\Lambda_{q}^{\prime}<0$. Since firms will not invest in frequency when this leads to an increase in the own generalized price, this is the relevant case, which ensures that $\partial p_{j} / \partial f_{i}<0$ (the proof is analogue to the proof of Lemma 4 ). The second term is positive in sign, which means that the sum of these two terms and thus the change in the rival's generalized prices caused by an increase in own frequency supply can be positive or negative. More specifically, it is positive when congestion effects are strong enough to ensure that $\Lambda_{q}^{\prime}>-\partial p_{j} / \partial f_{i}$. So, it may be that, in the presence of per-passenger congestion costs $\Lambda_{q}$, the strategic effects are reversed in the sense that carriers employ a fat-cat strategy (following the taxonomy of Fudenberg and Tirole (1984) once more). This is because, under these conditions, the rival's generalized prices can be increasing in own frequency, which then softens fare competition in the third stage. ${ }^{27}$ Thus, this provides another rationale for carriers to choose a positive per-flight charge in the first stage, which is to mitigate strategic oversupply of frequencies.

Welfare-optimal fares are still zero in the present scenario; recall that congestion is related to flight frequencies and not passenger numbers, which explains this result. Assume, again, that welfareoptimal frequencies are determined by the first-order condition $\partial W / \partial f_{i}=0$. In the case of congestion, this first-order condition can be written as $-\left(D \Lambda_{q}^{\prime}+f \Lambda_{\pi}^{\prime}\right)-\Gamma^{\prime} D_{i}-\left(c+\Lambda_{\pi}\right)=0$. The first two terms

\footnotetext{
${ }^{27}$ That firms may have an incentive to "create" congestion in order to soften price competition has also been found by De Borger and Van Dender (2006). They consider a framework where firms choose capacities before they engage in price competition.
} 
on the left-hand-side show the effect of a marginal frequency increase on the congestion costs of all passengers and flights. The third bracketed term shows the reduction in schedule delay costs for own passengers. The final two terms show the increase in the carriers operating and congestion costs associated with the marginal increase in own frequency. In the social optimum, these terms all add up to zero, that is, the difference between the reduction in schedule delay costs and the increase in congestion costs to all passengers and flights should be equal to the per-flight operating costs including the per-flight congestion cost. The full internalization of congestion externalities and the mitigation of strategic oversupply of frequencies are, thus, also in the interest of the social maximizer.

The following result illustrates:

Proposition 4 The carrier's preferred airport charges structure is equal to the socially preferred structure if and only if the optimized per-flight charge can be written as:

$$
\tau_{f}=\left(p_{i}-\tau_{q}\right) \frac{\partial D_{i}}{\partial \eta_{j}}\left(\frac{\partial p_{j}}{\partial f_{i}}+\Lambda_{q}^{\prime}\right)+\frac{1}{2}\left(D \Lambda_{q}^{\prime}+f \Lambda_{\pi}^{\prime}\right)+\left(\left(D \Lambda_{q}^{\prime}+f \Lambda_{\pi}^{\prime}\right)+D_{i} \Gamma^{\prime}+\left(c+\Lambda_{\pi}\right)\right)\left(\Delta_{\bar{f}}-1\right) .
$$

The right-hand side shows how the per-flight charge can be used to mitigate strategic over- or under-supply of frequencies, the first term, and congestion externalities, the second term. The righthand side is strictly positive in sign if an increase in own frequencies increases the rival's generalized price. It can be positive or negative in sign, otherwise. Altogether, this implies that it is not sufficient to check the statements of carriers' preferences in order to derive insights about the social benefits of airport charges structures: No matter whether carriers express a preference for positive, zero or even negative per-flight charges, all these cases can but do not necessarily have to be consistent with the social viewpoint. Only if congestion costs are absent, i.e., when $\Lambda_{q}^{\prime}=\Lambda_{\pi}^{\prime}=0$, and carriers express a preference for a positive per-flight charge one can infer that the carriers' and the social viewpoints are inconsistent. This is because in this case the right-hand side of (8) is strictly positive in sign.

\section{Conclusions}

Airlines have expressed their preference for per-passenger based airport charges over per-flight based airport charges. Czerny and Zhang (2015a) showed that the carriers' and the social preferences are in line if the carriers' preferred per-flight charge is equal to zero, which is true for both uncongested and congested airports. This indicates that the carriers' expressed preferences may indeed be consistent with the social objective of welfare maximization. However, Czerny and Zhang's analysis was confined to monopoly markets, while many airline markets are in fact oligopolistic. The present study therefore complements their analysis, and the results show that the evaluation of airport charges structures indeed depends on carrier market structures. Furthermore, it depends also on the timing of fare and frequency choices (while the timing is not relevant in the monopoly case). 
More specifically, if carrier markets are oligopolistic and frequencies are fixed, for example, at slot-constrained airports, a move from a system that relies fully on per-flight charges towards a perpassenger based charging scheme can be used as a device to implement monopoly fares downstream. The desire for the increased use of positive per-passenger charges should therefore be critically reviewed by policy makers at slot-constrained airports. On the other hand, if frequencies are endogenously determined before fares, the monopoly result on the consistency between the carriers' and the social preferences for airport charges structures can prevail at uncongested airports. This is because carriers strategically reduce frequency supply in order to soften competition in the pricing stage, which leads to a prisoner's dilemma situation for carriers and reduces social welfare. Positive per-passenger charges can help mitigate the prisoner's dilemma problem for carriers and increase welfare because the revenue derived from these charges can be used to lower the per-flight charge and thus stimulate frequency supply. In this case, the carriers' preferences for positive per-passenger based airport charges again indicates that these may be also preferable from the social viewpoint.

The results presented in this paper are in general inconclusive when airports allocate runway capacity based on the first-come-first-serve principle. More specifically, with congestion, it is unclear whether carriers actually have an incentive to strategically over- or under-supply frequencies. This is because an increase in frequencies then has two effects: it reduces schedule delays which strengthens competition in the pricing stage, but it also raises congestion, which softens competition in the pricing stage. Under these conditions it is difficult to infer the consistency of the airlines' and the social preferences for airport charges structures from the airlines' preference structures. This indicates that a case-by-case investigation may be needed for these airports.

The present analysis has abstracted away from a discussion of passenger types in terms of time valuations. The role of time valuations for airline ticket prices and airport-charges structures without recognizing the issue of airport cost recovery have been analyzed by Czerny and Zhang (2011, 2014a, 2014b, and 2015b). ${ }^{28}$ Czerny and Zhang (2015a) show that carriers may benefit less from positive per-passenger charges when the business passengers' valuations of schedule delays are high relative to the leisure passengers' valuations. This is because exact internalization of reductions in schedule delay costs is not ensured, if carriers cannot price discriminate between business and leisure passengers, which may translate into a preference for a low per-passenger charge and high per-flight charge relative to a situation with discriminating fares. While Czerny and Zhang (2015a) concentrate on a monopoly, we believe that their results on the role of time valuations and price discrimination are largely independent of whether monopoly or oligopoly market structures are considered. This means that also with oligopolistic carriers, low per-flight charges can be useful to improve the carriers' incentive to invest in frequency supply from the social viewpoint.

\footnotetext{
${ }^{28}$ There is good evidence that business passengers incur high time valuations relative to leisure passengers (e.g., Morrison, 1987; Morrison and Winston, 1989; USDOT, 1997; and Pels et al., 2003).
} 
The present analysis has further abstracted away from the presence of transfer passengers, i.e., passengers who use airport infrastructure to switch between connecting flights, which can reach more than 50 percent at a number of hub airports in the United States (Lin and Zhang, 2016). Incorporating transfer passengers (as opposed to local passengers) would introduce the investigation of per-flight versus per-passenger charges in a hub-spoke network, which is an interesting topic for future study. Moreover, by concentrating on a given number of carriers we have abstracted away from market entry and the possibility that incumbent carriers would use fares and frequencies to deter market entry. It would be useful to extend the analysis in a way that captures the possibility of market entry in a future study.

Finally, the present study employed a scenario where aircraft capacities are given and large enough to be non-binding in equilibrium. Such a set of assumptions, or an alternative set of assumptions where load factors are considered as fixed, are standard in the air transport literature. Studies only recently started to analyze more realistic and complex models with endogenous load factors (e.g., Czerny, Verhoef and Zhang, 2015; and Czerny, Van den Berg and Verhoef, 2016). The analysis of airport charges structures in an environment with endogenous load factors would be a worthwhile avenue for future research. 


\section{References}

ACI (2008). ACI Airport Economics Survey 2008. Airport Council International.

Allonen, M. (2013), Operating Lease or Purchase Analysis - Case: An Acquisition of Airbus A330-300 for Finnair. Master's Thesis, School of Business, Aalto University, Finland.

Armstrong, M. (1998). Network interconnection in telecommunications. Economic Journal 108: 545564.

ATRS (2012), The ATRS (Air Transport Research Society) Airport Performance Benchmarking Report: Global Standards for Airport Excellence, 3-Volume Report. Published by the Centre for Transportation Studies, Sauder School of Business, University of British Columbia, Vancouver, BC.

Basso, L. J. and Zhang, A. (2007a), Congestible facility rivalry in vertical structures, Journal of Urban Economics, 61: 218-237.

Basso, L. J. and Zhang, A. (2007b), An interpretative survey of analytical models of airport pricing, in: Lee, D. (ed.), Advances in Airline Economics, Vol. 2, pp. 89-124, Amsterdam: Elsevier.

Borenstein, S. (1985), Price discrimination in free-entry markets, RAND Journal of Economics, 16: 380-397.

Bourjade, S., Huc, R. and Muller-Vibes, C. (2017), Leasing and profitability: Empirical evidence from the airline industry, Transportation Research Part A: Policy and Practice, 97: 30-46.

Brander, J. A. and Zhang, A. (1990), Market conduct in the airline industry: An empirical investigation, RAND Journal of Economics, 21: 567-583.

Brueckner, J. K. (2002), Airport congestion when carriers have market power, American Economic Review, 92: 1357-1375.

Brueckner, J. K. (2004). Network structure and airline scheduling. Journal of Industrial Economics $52,291-312$.

Brueckner, J. K. (2010), Schedule competition revisited, Journal of Transport Economics and Policy, 44: $261-285$.

Brueckner, J. K. and Flores-Fillol, R. (2007), Airline schedule competition, Review of Industrial Organization, 30: 161-177.

Brueckner, J. K. and Luo, D. (2014), Measuring strategic firm interaction in product-quality choices: The case of airline flight frequency, Economics of Transportation, 3(1): 102-115. 
Bulow, J. I., Geanakoplos, J. D. and Klemperer, P. D. (1985), Multimarket oligopoly: strategic substitutes and complements, Journal of Political Economy, 93: 488-511.

Bush, H. and Starkie, D. (2014), Competitive drivers towards improved airport/airline relationships, Journal of Air Transport Management, 41: 45-49.

Choo, Y. Y. (2014), Factors affecting aeronautical charges at major US airports, Transportation Research Part A: Policy and Practice, 62: 54-62.

Czerny, A. I., Guiomard, C. and Zhang, A. (2016), Single-till versus dual-till regulation of airports: Where do academics and regulators (dis)agree? Journal of Transport Economics and Policy, 50(4): $350-368$.

Czerny, A. I. and Zhang, A. (2011), Airport congestion pricing and passenger types, Transportation Research Part B: Methodological, 45: 595-604.

Czerny, A. I. and Zhang, A. (2014a), Airport peak-load pricing revisited: The case of peak and uniform tolls, Economics of Transportation 3: 90-101.

Czerny, A. I. and Zhang, A. (2014b), Airport congestion pricing when airlines price discriminate, Transportation Research Part B: Methodological, 65: 77-89.

Czerny, A. I. and Zhang, A. (2015a), How to mix per-flight and per-passenger based airport charges, Transportation Research Part A: Policy and Practice 71: 77-95.

Czerny, A. I. and Zhang, A. (2015b), Third-degree price discrimination in the presence of congestion externality, Canadian Journal of Economics 48: 1430-1455.

Czerny, A. I., Verhoef, E. T. and Zhang, A. (2015). A theory of continuous uncertainty types. Tinbergen Institute Discussion Paper TI 2015-065/VIII.

Czerny, A. I., Van Den Berg, V. A. C., Verhoef, E. T. (2016). Carrier collaboration with endogenous fleets and load factors when networks are complementary. Transportation Research Part B 94, 285-297.

Daniel, J. I. (1995), Congestion pricing and capacity of large hub airports: A bottleneck model with stochastic queues, Econometrica, 63: 327-370.

De Borger, B. and Van Dender, K. (2006). Prices, capacities and service levels in a congestible Bertrand duopoly. Journal of Urban Economics 60, 264-283.

Douglas, W. D. and Miller, J. C. (1974). Quality competition, industry equilibrium, and efficiency in the price-constrained airline market. American Economic Review 64, 657-669. 
Fudenberg, D. and Tirole, J. (1984), The fat-cat effect, the puppy-dog ploy, and the lean and hungry look, American Economic Review, 74: 361-366.

Gillen, D., Jacquillat, A. and Odoni, A. R. (2016). Airport demand management: The operations research and economics perspectives and potential synergies. Transportation Research Part A 94, 495-513.

ICAO (2012), ICAO's Policies on Charges for Airports and Air Navigation Services, ninth edition, Doc 9082, International Civil Aviation Organisation.

Laffont, J.-J., Rey, P. and Tirole, J. (1998a), Network competition: I. Overview and nondiscriminatory pricing, RAND Journal of Economics 29: 1-37.

Laffont, J.-J., Rey, P. and Tirole, J. (1998b), Network competition: II. Price discrimination, RAND Journal of Economics 29: 38-56.

Lazarev, J. (2013), The welfare effects of intertemporal price discrimination: An empirical analysis of airline pricing in U.S. monopoly markets, mimeo, Graduate School of Business, Stanford University.

Lin, M. H. and Zhang, A. (2016), Hub congestion pricing: Discriminatory passenger charges, Economics of Transportation 5: 37-48.

Morrison, S. A. (1987), The equity and efficiency of runway pricing, Journal of Public Economics, 34: 45-60.

Morrison, S. A. and Winston, C. (1989), Enhancing the performance of the deregulated air transportation system, Brookings Papers on Economic Activity: Microeconomics, 61-112.

Oum, T.H., Zhang, A. and Zhang, Y. (2000), Optimal demand for operating lease of aircraft, Transportation Research Part B: Methodological, 34: 17-29.

Pels, E., Nijkamp, P. and Rietveld, P. (2003), Access to and competition between airports: A case study for the San Francisco Bay area, Transportation Research Part A: Policy and Practice, 37(1): $71-83$.

Sheshinski, E. (1976), Price, quality and quantity regulation in monopoly, Economica, 43: 127-137.

Silva, H. and Verhoef, E. T. (2013), Optimal pricing of flights and passengers at congested airports and the efficiency of atomistic charges, Journal of Public Economics 106: 1-13.

Spence, E. (1975), Monopoly, quality and regulation, Bell Journal of Economics, 6: 417-429.

Stiglitz, J. E. (1998), An agenda for development in the twenty-first century, in: Pleskovic, B. and Stiglitz, J. E. (eds.), Annual World Bank Conference 1997, The World Bank, Washington D. C., pp. $17-32$. 
Topkis, D. (1998), Supermodularity and Complementarity, Princeton University Press, Princeton, New Jersey.

USDOT (1997), The Value of Saving Travel Time: Departmental Guidance for Conducting Economic Evaluations, The U.S. Department of Transportation, Washington, DC.

Vasigh, B., Fleming, K. and Humphreys, B. (2015), Foundations of Airline Finance: Methodology and Practice, 2nd edition, Routledge, England.

Vives, X. (1999), Oligopoly Pricing - Old Ideas and New Tools, The MIT Press.

Zhang, A. (2012), Airport Improvement fees, benefit spillovers, and land value capture mechanisms, in: Ingram, G. K. and Hong, Y.-H. (eds.), Value Capture and Land Policies, Lincoln Institute of Land Policies, 323-348.

Zhang, A. and Czerny, A. I. (2012), Airports and airlines economics and policy: An interpretive review of recent research, Economics of Transportation, 1: 15-34.

Zhang, A. and Zhang, Y. (2006), Airport capacity and congestion when carriers have market power, Journal of Urban Economics, 60: 229-247. 


\section{Appendix}

\section{A Proofs}

Proof of Lemma 1. Totally differentiating the equilibrium conditions $B_{i}=\eta_{i}$ with respect to fares yields the system of equations

$$
\begin{aligned}
& d B_{1}=B_{11} d q_{1}+B_{12} d q_{2}-d \eta_{1}=0 \\
& d B_{2}=B_{21} d q_{1}+B_{22} d q_{2}=0 .
\end{aligned}
$$

for $i=1$. In matrix form, this can be rewritten as

$$
\left(\begin{array}{ll}
B_{11} & B_{12} \\
B_{21} & B_{22}
\end{array}\right)\left(\begin{array}{l}
d q_{1} \\
d q_{2}
\end{array}\right)=d \eta_{i}\left(\begin{array}{l}
1 \\
0
\end{array}\right),
$$

where the determinant of the first matrix on the left-hand side, denoted as $\Psi$ with

$$
\Psi \equiv \operatorname{det}\left(\begin{array}{ll}
B_{11} & B_{12} \\
B_{21} & B_{22}
\end{array}\right)=B_{11} B_{22}-B_{12}^{2}
$$

is strictly positive by Assumption 1. Carmer's rule can be applied to derive

$$
\begin{aligned}
& \frac{d q_{1}}{d \eta_{1}}=\frac{1}{\Psi} \operatorname{det}\left(\begin{array}{cc}
1 & B_{12} \\
0 & B_{22}
\end{array}\right)=\frac{B_{22}}{\Psi}, \\
& \frac{d q_{2}}{d \eta_{1}}=\frac{1}{\Psi} \operatorname{det}\left(\begin{array}{ll}
B_{11} & 1 \\
B_{21} & 0
\end{array}\right)=-\frac{B_{21}}{\Psi} .
\end{aligned}
$$

and $d\left(q_{1}+q_{2}\right) / d \eta_{1}=\left(B_{22}-B_{21}\right) / \Psi$. The effect of changes in the generalized price $\eta_{2}$ on demands $D_{1}$ and $D_{2}$ can be derived analogously.

Proof of Lemma 2. Totally differentiating the first-order conditions, $\partial \pi_{i} / \partial p_{i}=0$, with respect to fares and the per-passenger charge yields the system of equations

$$
\begin{aligned}
d \frac{\partial \pi_{1}}{\partial p_{1}} & =\frac{\partial^{2} \pi_{1}}{\partial p_{1}^{2}} d p_{1}+\frac{\partial^{2} \pi_{1}}{\partial p_{1} \partial p_{2}} d p_{2}+\frac{\partial^{2} \pi_{1}}{\partial p_{1} \partial \tau_{q}} d \tau_{q}=0 \\
d \frac{\partial \pi_{2}}{\partial p_{2}} & =\frac{\partial^{2} \pi_{2}}{\partial p_{2} \partial p_{1}} d p_{1}+\frac{\partial^{2} \pi_{2}}{\partial p_{2}^{2}} d p_{2}+\frac{\partial^{2} \pi_{2}}{\partial p_{2} \partial \tau_{q}} d \tau_{q}=0 .
\end{aligned}
$$

Using symmetry, this can be simplified as

$$
\left(\frac{\partial^{2} \pi_{i}}{\partial p_{i}^{2}}+\frac{\partial^{2} \pi_{i}}{\partial p_{i} \partial p_{j}}\right) d p_{i}+\frac{\partial^{2} \pi_{i}}{\partial p_{i} \partial \tau_{q}} d \tau_{q}=0
$$

Rearranging then leads to

$$
\frac{d p_{i}}{d \tau_{q}}=-\frac{\partial^{2} \pi_{i}}{\partial p_{i} \partial \tau_{q}} /\left(\frac{\partial^{2} \pi_{i}}{\partial p_{i}^{2}}+\frac{\partial^{2} \pi_{i}}{\partial p_{i} \partial p_{j}}\right)
$$

where $\partial^{2} \pi_{i} / \partial p_{i} \partial \tau_{q}=-\partial D_{i} / \partial \eta_{i}>0$ and $\partial^{2} \pi_{i} / \partial p_{i}^{2}+\partial^{2} \pi_{i} / \partial p_{i} \partial p_{j}<0$ by Assumption 2, which ensures that equilibrium fares are increasing in the per-passenger charge. 
Proof of Proposition 1 Abstract away from frequency costs (and schedule delays) because frequencies are fixed by assumption. Then individual profits can be written as $\left(p_{i}-\tau_{q}\right) D_{i}\left(p_{1}, p_{2}\right)$ and joint profits are $\left(p_{1}-\tau_{q}\right) D_{1}\left(p_{1}, p_{2}\right)+\left(p_{2}-\tau_{q}\right) D_{2}\left(p_{1}, p_{2}\right)$. If one abstracts away from passenger based charges, then joint profits are $p_{1} D_{1}\left(p_{1}, p_{2}\right)+p_{2} D_{2}\left(p_{1}, p_{2}\right)$. Recall that the total payments to the airport are always the same and given by $F$; so, the last expression is the objective of carriers when they jointly evaluate airport charges structures.

The first-order conditions for best responses in terms of prices evaluated at the monopoly outcome are implicitly determined by

$$
D_{i}\left(p_{1}, p_{2}\right)+\left(p-\tau_{q}\right) \frac{\partial D_{i}}{\partial p_{i}}=0 .
$$

The first-order condition for the optimal collusive prices are

$$
q_{i}\left(p_{1}, p_{2}\right)+p \frac{\partial D_{i}}{\partial p_{i}}+p \frac{\partial D_{j}}{\partial p_{i}}=0
$$

The difference of the equations can be written as

$$
\left(q_{i}\left(p_{1}, p_{2}\right)+p \frac{\partial q_{i}}{\partial p_{i}}+p \frac{\partial q_{j}}{\partial p_{i}}\right)-\left(q_{i}\left(p_{1}, p_{2}\right)+\left(p-\tau_{q}\right) \frac{\partial q_{i}}{\partial p_{i}}\right)=p \frac{\partial q_{j}}{\partial p_{i}}+\tau_{q} \frac{\partial q_{i}}{\partial p_{i}}=0
$$

Solving leads to the optimal per-passenger charge from the carriers' viewpoint $\tau_{q}=-p \cdot\left(\partial D_{j} / \partial p_{i}\right) /\left(\partial D_{i} / \partial p_{i}\right)$. This shows that the per-passenger based charged can be used to internalize the effect of own prices on the rival carrier's profit in order to reach the monopoly solution in an oligopolistic carrier market.

Proof of Lemma 3. Recall the carriers' first-order conditions in the third stage:

$$
\frac{\partial \pi_{i}}{\partial p_{i}}=D_{i}+\left(p_{i}-\tau_{q}\right) \frac{\partial D_{i}}{\partial \eta_{i}}=0
$$

The implicit-function theorem can be used to identify the effect of an increase in own frequency supply on own best responses in terms of fares:

$$
\frac{d p_{i}}{d f_{i}}=-\frac{\partial^{2} \pi_{i} / \partial p_{i} \partial f_{i}}{\partial^{2} \pi_{i} / \partial p_{i}^{2}}=-\frac{\partial^{2} \pi_{i} / \partial p_{i} \partial \eta_{i}}{\partial^{2} \pi_{i} / \partial p_{i}^{2}} \cdot \Gamma^{\prime}
$$

with $\partial^{2} \pi_{i} / \partial p_{i} \partial \eta_{i}, \partial^{2} \pi_{i} / \partial p_{i}^{2}<0$ by Assumption 2. The right-hand side of (23) is, thus, positive. The effect of an increase of own frequencies on own generalized prices can be written as

$$
\frac{d \eta_{i}}{d f_{i}}=\frac{d p_{i}}{d f_{i}}+\Gamma^{\prime}=\left(1-\frac{\partial^{2} \pi_{i} / \partial p_{i} \partial \eta_{i}}{\partial^{2} \pi_{i} / \partial p_{i}^{2}}\right) \cdot \Gamma^{\prime}
$$

with $\partial^{2} \pi_{i} / \partial p_{i}^{2}<\partial^{2} \pi_{i} / \partial p_{i} \partial \eta_{i}$ because $\partial^{2} \pi_{i} / \partial p_{i}^{2}-\partial^{2} \pi_{i} / \partial p_{i} \partial \eta_{i}=-\partial D_{i} / \partial \eta_{i}$. The right-hand side is, thus, negative because own schedule delay costs are decreasing in own frequency supply. Altogether this establishes part (i).

The implicit function theorem can further be used to

$$
\frac{d p_{j}}{d f_{i}}=-\frac{\partial^{2} \pi_{j} / \partial p_{j} \partial f_{i}}{\partial^{2} \pi_{j} / \partial p_{j}^{2}}=-\frac{\partial^{2} \pi_{j} / \partial p_{j} \partial \eta_{i}}{\partial^{2} \pi_{j} / \partial p_{j}^{2}} \cdot \Gamma^{\prime},
$$

where $\partial^{2} \pi_{j} / \partial p_{j} \partial \eta_{i}>0$, which means that the right-hand side is negative and establishes part (ii). 
Proof of Lemma 4. Totally differentiating the first-order conditions (22) with respect to prices and own frequency supply yields the system of equations

$$
\begin{aligned}
& d \frac{\partial \pi_{1}}{\partial p_{1}}=\frac{\partial^{2} \pi_{1}}{\partial p_{1}^{2}} d p_{1}+\frac{\partial^{2} \pi_{1}}{\partial p_{1} \partial p_{2}} d p_{2}+\frac{\partial^{2} \pi_{1}}{\partial p_{1} \partial f_{1}} d f_{1}=0 \\
& d \frac{\partial \pi_{2}}{\partial p_{2}}=\frac{\partial^{2} \pi_{2}}{\partial p_{2} \partial p_{1}} d p_{1}+\frac{\partial^{2} \pi_{2}}{\partial p_{2}^{2}} d p_{2}+\frac{\partial^{2} \pi_{2}}{\partial p_{2} \partial f_{1}} d f_{1}=0
\end{aligned}
$$

In matrix form, this can be written as

$$
\left(\begin{array}{cc}
\frac{\partial^{2} \pi_{1}}{\partial p_{1}^{2}} & \frac{\partial^{2} \pi_{1}}{\partial p_{1} \partial p_{2}} \\
\frac{\partial^{2} \pi_{2}}{\partial p_{2} \partial p_{1}} & \frac{\partial^{2} \pi_{2}}{\partial p_{2}^{2}}
\end{array}\right)\left(\begin{array}{c}
d p_{1} \\
d p_{2}
\end{array}\right)=-d f_{1}\left(\begin{array}{c}
\frac{\partial^{2} \pi_{1}}{\partial p_{1} \partial f_{1}} \\
\frac{\partial^{2} \pi_{2}}{\partial p_{2} \partial f_{1}}
\end{array}\right),
$$

where the determinant of the first matrix on the left-hand side, denoted as $\Xi_{1}$ with

$$
\Xi_{i} \equiv \operatorname{det}\left(\begin{array}{cc}
\frac{\partial^{2} \pi_{i}}{\partial p_{i}^{2}} & \frac{\partial^{2} \pi_{i}}{\partial p_{i} \partial p_{j}} \\
\frac{\partial^{2} \pi_{j}}{\partial p_{j} \partial p_{i}} & \frac{\partial^{2} \pi_{j}}{\partial p_{j}^{2}}
\end{array}\right)
$$

for $i=1,2$, is strictly positive by Assumption 2. Cramer's rule can be applied to derive

$$
\begin{aligned}
\frac{d p_{i}}{d f_{i}} & =\frac{1}{\Xi_{i}} \operatorname{det}\left(\begin{array}{cc}
-\frac{\partial^{2} \pi_{i}}{\partial p_{i} \partial f_{i}} & \frac{\partial^{2} \pi_{i}}{\partial p_{i} \partial p_{j}} \\
-\frac{\partial^{2} \pi_{j}}{\partial p_{j} \partial f_{i}} & \frac{\partial^{2} \pi_{j}}{\partial p_{j}^{2}}
\end{array}\right) \\
& =\frac{1}{\Xi_{i}} \operatorname{det}\left(\begin{array}{cc}
-\frac{\partial^{2} \pi_{i}}{\partial p_{i} \partial \eta_{i}} \Gamma^{\prime}\left(f_{i}\right) & \frac{\partial^{2} \pi_{i}}{\partial p_{i} \partial p_{j}} \\
-\frac{\partial^{2} \pi_{j}}{\partial p_{j} \partial \eta_{i}} \Gamma^{\prime}\left(f_{i}\right) & \frac{\partial^{2} \pi_{j}}{\partial p_{j}^{2}}
\end{array}\right) \\
& =-\frac{\Gamma^{\prime}\left(f_{i}\right)}{\Xi_{i}}\left(\frac{\partial^{2} \pi_{i}}{\partial p_{i} \partial \eta_{i}} \frac{\partial^{2} \pi_{j}}{\partial p_{j}^{2}}-\frac{\partial^{2} \pi_{i}}{\partial p_{i} \partial p_{j}} \frac{\partial^{2} \pi_{j}}{\partial p_{j} \partial \eta_{i}}\right)
\end{aligned}
$$

where the right-hand side is positive because it is the product of two terms that are positive by Assumption 2. Using $\partial^{2} \pi_{j} / \partial p_{j} \partial p_{i}=\partial^{2} \pi_{j} / \partial p_{j} \partial \eta_{i}$, it holds that

$$
\begin{aligned}
\frac{d p_{j}}{d f_{i}} & =\frac{1}{\Xi_{i}} \operatorname{det}\left(\begin{array}{cc}
\frac{\partial^{2} \pi_{i}}{\partial p_{i}^{2}} & -\frac{\partial^{2} \pi_{i}}{\partial p_{i} \partial \eta_{i}} \Gamma^{\prime}\left(f_{i}\right) \\
\frac{\partial^{2} \pi_{j}}{\partial p_{j} \partial p_{i}} & -\frac{\partial^{2} \pi_{j}}{\partial p_{j} \partial \eta_{i}} \Gamma^{\prime}\left(f_{i}\right)
\end{array}\right) \\
& =-\frac{\Gamma^{\prime}\left(f_{i}\right)}{\Xi_{i}}\left(\frac{\partial^{2} \pi_{i}}{\partial p_{i}^{2}}-\frac{\partial^{2} \pi_{i}}{\partial p_{i} \partial \eta_{i}}\right) \frac{\partial^{2} \pi_{j}}{\partial p_{j} \partial \eta_{i}},
\end{aligned}
$$

where the right-hand side is negative in sign by the strategic complementarity of fares. Using symmetry $\left(f_{1}=f_{2}=\bar{f}\right)$, the effect of an increase in the overall level of frequency supplies on equilibrium fares can be derived as

$$
\frac{d p_{i}}{d f_{i}}+\frac{d p_{i}}{d f_{j}}=-\frac{\Gamma^{\prime}\left(f_{i}\right)}{\Xi_{i}}\left(\frac{\partial^{2} \pi_{i}}{\partial p_{i} \partial \eta_{i}}+\frac{\partial^{2} \pi_{j}}{\partial p_{j} \partial \eta_{i}}\right)\left(\frac{\partial^{2} \pi_{j}}{\partial p_{j}^{2}}-\frac{\partial^{2} \pi_{j}}{\partial p_{j} \partial \eta_{i}}\right),
$$

where the right-hand side is positive by Assumption 2 .

Proof of Lemma 5. Totally differentiating the first-order conditions in (3) with respect to frequencies and the per-flight charges and applying Cramer's rule yields:

$$
\frac{d f_{i}}{d \tau_{f}}=\operatorname{det}\left(\begin{array}{cc}
1 & \frac{\partial^{2} \pi_{i}}{\partial f_{i} \partial f_{j}} \\
1 & \frac{\partial^{2} \pi_{j}}{\partial f_{j}^{2}}
\end{array}\right) / \operatorname{det}\left(\begin{array}{cc}
\frac{\partial^{2} \pi_{i}}{\partial f_{i}^{2}} & \frac{\partial^{2} \pi_{i}}{\partial f_{i} \partial f_{j}} \\
\frac{\partial^{2} \pi_{i}}{\partial f_{j} \partial f_{i}} & \frac{\partial^{2} \pi_{j}}{\partial f_{j}^{2}}
\end{array}\right) .
$$

The right-hand side is negative by the contraction conditions for frequencies. 
Proof of Proposition 4. Assume that the optimal per-passenger charge from the carriers' viewpoint is determined by the first-order condition $\partial \pi / \partial \tau_{q}=0$. Using symmetry, this condition can be written as

$$
\Delta_{p} D_{i}+p \frac{\partial D_{i}}{\partial \eta_{i}} \underbrace{\left(\Delta_{p}+\Delta_{\bar{f}}\left(\Gamma^{\prime}+2 \Lambda_{q}^{\prime}\right)\right)}_{\equiv \Delta_{\eta \Lambda}}-\Delta_{\bar{f}}\left(c+\Lambda_{\pi}+2 f_{i} \Lambda_{\pi}^{\prime}\right)=0 .
$$

The first two terms on the left-hand side show the change in individual revenues associated with a marginal increase in the per-passenger charge. The third term shows the increase in individual frequency costs associated with a marginal increase in the per-passenger charge. The change in the generalized prices, $\Delta_{\eta \Lambda}$, incorporates the change in the passengers' congestion costs associated with an increase in equilibrium frequency levels given by $2 \Lambda_{q}^{\prime}$. The change in flight costs, $c+\Lambda_{\pi}+2 f_{i} \Lambda_{\pi}^{\prime}$, incorporates the corresponding increase in the airlines' congestion costs $2 f_{i} \Lambda_{\pi}^{\prime}$. The terms $\Lambda_{q}^{\prime}$ and $f_{i} \Lambda_{\pi}^{\prime}$ are multiplied by a factor of 2 because they depend on the total amount of flights $f$ with $f=2 f_{i}$. and an increase in equilibrium frequency levels increases frequencies of airlines 1 and 2 .

To analyze the distinct views on per-passenger charges from the carriers' and the social viewpoints, we consider the unifying objective $V \equiv \pi+\phi C S$, again. The change in consumer surplus associated with the change in the per-passenger charge conditional on airport cost recovery can be written as the derivative $\partial C S / \partial \tau_{q}=-\Delta_{\eta \Lambda} D$. This derivative can then be used to write the first-order condition for the optimization of the unifying objective $V$ as

$$
\Delta_{p} D_{i}-\Delta_{\bar{f}}\left(c+\Lambda_{\pi}+2 f_{i} \Lambda_{\pi}^{\prime}\right)+\Delta_{\eta \Lambda}\left(p \frac{\partial D_{i}}{\partial \eta_{i}}-\phi D_{i}\right)=0
$$

The left-hand side implies that the carriers' and the social viewpoints will lead to identical airport charges structures only if $\Delta_{\eta \Lambda}=0$ is satisfied in the carriers' and the social optimum. Using $\Delta_{\eta \Lambda}=0$ (i.e., $\left.\Delta_{p}=-\Delta_{\bar{f}}\left(\Gamma^{\prime}+2 \Lambda_{q}^{\prime}\right)\right)$ the first two terms on the left-hand side can be written as $\Delta_{\bar{f}}\left(-D_{i}\left(\Gamma^{\prime}+2 \Lambda_{q}^{\prime}\right)-\left(c+\Lambda_{\pi}+2 f_{i} \Lambda_{\pi}^{\prime}\right)\right)$. They must be equal to zero in order to ensure that the airliines' and the social viewpoints are consistent. Together with the first-order condition for the profit-maximizing frequency $(7)$, this implies:

$$
\begin{aligned}
\left(p_{i}-\tau_{q}\right) \frac{\partial D_{i}}{\partial \eta_{j}}\left(\frac{\partial p_{j}}{\partial f_{i}}+\Lambda_{q}^{\prime}\right) & -\frac{1}{2}\left(D \Lambda_{q}^{\prime}+f \Lambda_{\pi}^{\prime}\right)-D_{i} \Gamma^{\prime}-\left(\tau_{f}+c+\Lambda_{\pi}\right) \\
& =\Delta_{\bar{f}}\left(-\left(D_{i} \Lambda_{q}^{\prime}+f_{i} \Lambda_{\pi}^{\prime}\right)-D_{i} \Lambda_{q}^{\prime}-D_{i} \Gamma^{\prime}-\left(c+\Lambda_{\pi}+f_{i} \Lambda_{\pi}^{\prime}\right)\right)
\end{aligned}
$$

Solving for the optimal per-flight charge, rearranging and expanding yields (8). 


\section{B Numerical Examples}

\section{B.1 Fixed Frequencies and $n$ Firms}

To illustrate the conflicting views of the social optimizer and oligopoly carriers on the per-passenger charges, consider now that there are $n \geq 1$ carriers. Passenger benefits are

$$
B=\alpha \sum_{i} q_{i}-\frac{\beta}{2} \sum_{i} q_{i}^{2}-\gamma \sum_{j \neq i} q_{i} q_{j}
$$

with $\alpha>0$ and $\beta>\gamma>0$. Demands can then be derived as $D_{i}=a-b \eta_{i}+(n-1) d \eta_{j}$ with

$$
a \equiv \frac{\alpha}{\beta+(n-1) \gamma}, b \equiv \frac{\beta+(n-2) \gamma}{(\beta+(n-1) \gamma)(\beta-\gamma)} \text { and } d \equiv \frac{\gamma}{(\beta+(n-1) \gamma)(\beta-\gamma)},
$$

which implies $a>0$ and $b>(n-1) d>0 .{ }^{29}$ Schedule delay costs are $\Gamma(\bar{f})=1 / \bar{f}$. Using the first-order conditions $\partial \pi_{i} / \partial p_{i}=0$ and symmetry, the equilibrium fares can be derived as

$$
p\left(\tau_{q}\right)=\frac{\bar{f} \cdot\left((\beta+(n-2) \gamma) \tau_{q}+\alpha(\beta-\gamma)\right)-(\beta-\gamma)}{\bar{f} \cdot(2 \beta+(n-3) \gamma)} .
$$

It can be checked that equilibrium fares are increasing in the per-passenger charge and decreasing in the number of carriers.

To derive the optimal per-passenger charges conditional on airport cost-recovery from the carriers' viewpoint, substitute $p$ for $p_{i}$ in the aggregate carrier profit function, which yields the aggregate carrier profit as a function of the per-passenger charge, $n\left(p\left(\tau_{q}\right) D_{i}-c \bar{f}\right)-F$. The optimal per-passenger charge from the carriers' viewpoint then becomes

$$
\arg \max _{\tau_{q}} n\left(p\left(\tau_{q}\right) D_{i}-c \bar{f}\right)-F=\frac{(n-1)(\alpha-1 / \bar{f}) \gamma}{2(\beta+(n-2) \gamma)} .
$$

Since the airport and the carrier cost-recovery constraints are binding from the social viewpoint, the optimal per-passenger charge from the social viewpoint can be derived as $\min \left\{\tau_{q}: n\left(p\left(\tau_{q}\right) D_{i}-c \bar{f}\right)-F=0\right\}$.

Figure 1 displays optimal per-passenger charges from the carriers' viewpoint (solid line) and the social viewpoint (dashed line) depending on the carrier number for parameters $\alpha=2, \beta=1, \gamma=$ $1 / 2, \bar{f}=1, F=1 / 4$ and $c=1 / 20$. Note that airport-cost recovery can be achieved only if the carrier number is (strictly) less than seven. This is because competition drives down aggregate carrier profits for given per-passenger charges, which leaves less room for airport cost recovery by revenues from per-flight charges. The figure shows that the optimal per-passenger charges are positive from the carriers' viewpoint to ensure the maximization of aggregate carrier profits. In contrast, the charges are negative from the social viewpoint when competition is sufficiently weak (i.e., when $n<4$ ), but they become positive when markets are sufficiently competitive (i.e., when $n=4,5,6$ ). Altogether, the optimal airport-charges structure thus depends heavily on whether the carriers' viewpoint or the social viewpoint is taken. Specifically, the carrier's optimal per-passenger charges are clearly excessive from the social viewpoint when frequencies are given.

\footnotetext{
${ }^{29}$ See Vives (1999) for the derivations.
} 
Figure 1: Optimal per-passenger charges from the carriers' viewpoint (solid line) and the social viewpoint (dashed line). Parameters: $\alpha=2, \beta=1, \gamma=1 / 2, \bar{f}=1, v=1, F=1 / 10, c=1 / 20$.

Figure 2: Iso carrier and iso airport profit functions (dashed and solid lines, respectively) and optimal airport charges structures from the carriers' viewpoint for: (i) a simultaneous choice of frequencies and fares without congestion (equilibrium carrier profit is 0.22 ), (ii) the sequential choice of frequencies and fares without congestion (equilibrium carrier profit is 0.21 ), and (iii) the sequential choice of frequencies and fares with congestion (equilibrium carrier profit is 0.05 ). 


\section{B.2 Strategic Frequency Choice}

Figure 2 displays the iso carrier profit and iso airport profit functions (dashed and solid lines, respectively) and the carrier's preferred airport charges structures conditional on airport cost recovery (i.e., the iso-airport profit represents all combinations of airport charges that exactly ensure airport cost recovery). The figure contains three diagrams. The diagram on top shows the carriers' preferred airport charges structure when fares and frequencies are chosen simultaneouslyand congestion is absent. The diagram in the middle shows that corresponding charges structure for the case of a sequential game structure where frequencies are chosen in anticipation of the fare competition. The bottom diagram displays the preferred airport charges structure in the case of a sequential game structure with congestion. Parameters are $\alpha=7, \beta=1, \gamma=4 / 5, v=1 / 4, F=c=1 / 10$, and $n=2$. In the case of congestion, the generalized price is given by $\eta_{i}=p_{i}+v / f_{i}+f / 20$ (where $f=f_{1}+f_{2}$ ).

Consider the cases where congestion effects are absent (the two diagrams at the top of Figure 2). Observe that the carriers' optimal per-passenger charge is increased by the sequential relative to the simultaneous game structure. This is to counteract the puppy-dog strategy and the corresponding prisoner's dilemma situation in the second stage when frequencies are chosen before fares. While airport charges structures can be used to mitigate the negative effects of strategic frequency supply, individual carrier profits are still higher with the simultaneous relative to the sequential game structure (0.22 and 0.21 , respectively). This means that when frequencies are endogenously determined before fares, an increase in the per-passenger charge can mitigate but may not fully eliminate the effects of the strategic frequency choice on carrier profits.

Consider the cases with sequential game structures (the two diagrams at the bottom of Figure 2 ). Observe that the carriers' optimal per-passenger charge is reduced in the presence of congestion (carrier profits are 0.05) relative to the other case without congestion. This illustrates how carriers can use airport charges structures to internalize congestion externalities. 